\title{
Apontamentos sobre a indústria têxtil fluminense no contexto pós Segunda Guerra Mundial: padrões e peculiaridades de fábricas com vila operária
}

Notes on the textile industry of the state of Rio de Janeiro in the post World War II context: patterns and peculiarities of factories with workers' village Apuntes sobre la industria textil en el estado de Río de Janeiro en el contexto post Segunda Guerra Mundial: patrones y peculiaridades de fábricas con villa obrera

Notes sur l'industrie textile dans le contexte de l'après Seconde Guerre mondiale: modèles et particularités des usines avec village d'ouvriers

\section{Felipe Ribeiro}

\section{OpenEdition}

Journals

\section{Edição electrónica}

URL: http://journals.openedition.org/espacoeconomia/3269

DOI: 10.4000/espacoeconomia.3269

ISSN: 2317-7837

\section{Editora}

Núcleo de Pesquisa Espaço \& Economia

\section{Refêrencia eletrónica}

Felipe Ribeiro, «Apontamentos sobre a indústria têxtil fluminense no contexto pós Segunda Guerra Mundial: padrões e peculiaridades de fábricas com vila operária », Espaço e Economia [Online],

12 | 2018, posto online no dia 14 julho 2018, consultado o 19 abril 2019. URL : http://

journals.openedition.org/espacoeconomia/3269; DOI : 10.4000/espacoeconomia.3269

Este documento foi criado de forma automática no dia 19 Abril 2019.

(C) NUPEE 


\section{Apontamentos sobre a indústria têxtil fluminense no contexto pós Segunda Guerra Mundial: padrões e peculiaridades de fábricas com vila operária}

Notes on the textile industry of the state of Rio de Janeiro in the post World War II context: patterns and peculiarities of factories with workers' village Apuntes sobre la industria textil en el estado de Río de Janeiro en el contexto post Segunda Guerra Mundial: patrones y peculiaridades de fábricas con villa obrera

Notes sur l'industrie textile dans le contexte de l'après Seconde Guerre mondiale: modèles et particularités des usines avec village d'ouvriers

Felipe Ribeiro

\section{Introdução}

1 Em seu estudo pioneiro sobre a indústria têxtil no Brasil, publicado originalmente em 1957, o brasilianista Stanley Stein argumentou que, durante a Segunda Guerra Mundial (1939-1945), o setor de fiação e tecelagem de algodão havia ingressado "num período de grande prosperidade que ofuscou a 'era de ouro' das primeiras décadas do século XX" (STEIN, 1979, p.165 [1957]). ${ }^{1}$

2 Segundo ele, o contexto da guerra fomentou uma demanda mundial por tecidos de algodão, tendo em vista que os principais países fornecedores do produto no mercado de exportação estavam priorizando outros ramos industriais, principalmente o bélico. Dessa forma, os "empresários têxteis brasileiros foram surpreendidos com a oportunidade de abastecer a 
América Latina, a Europa e o Oriente Próximo", porém “com praticamente as mesmas instalações, equipamentos e técnicas empresariais dos anos críticos da década de trinta" (STEIN, 1979, p.167 [1957]).

3 As indústrias têxteis brasileiras também foram bastante beneficiadas com o chamado "esforço de guerra", conciliando um forte incremento na produção de tecidos com a supressão de diversos direitos trabalhistas, recentemente promulgados na Consolidação das Leis do Trabalho (CLT). Este bom momento gerou um rápido retorno financeiro aos empresários, já que o setor têxtil havia sido incluído no conjunto de outras indústrias consideradas de "interesse nacional" durante a guerra. Essa conjuntura favorável para o setor têxtil chegou a ser abordada em um memorando da Embaixada Americana, datado de 1944: "É evidente que a Lei de Mobilização [esforço de guerra] dá à indústria têxtil controle autocrático sobre a sua força de trabalho e que essa indústria recorre a esse controle para responder à pressão que podia vir de baixo para cima (...)" (COSTA, 1994. p.94).

4 O Brasil já havia assumido cotas de exportação de tecidos distribuídas pela United Relief and Rehabilitation Administration (UNRRA), uma representação das Nações Unidas para assistência e reabilitação mundial diante da escassez de abastecimento gerada pela guerra, e também cotas pelo Conselho Francês de Aprovisionamento (CFA). Diante deste cenário desafiador, mas com perspectivas promissoras, foram desenvolvidas uma série de ações de planejamento no âmbito do então Ministério do Trabalho, Indústria e Comércio, sobretudo a partir da criação da Comissão Executiva Têxtil (CETex), órgão responsável por orientar e dirigir essa mobilização de empresas de tecidos no país (Brasil, Decreto-Lei $\left.\mathrm{n}^{\circ} 6.688,13 / 07 / 1944\right)$.

5 Por meio de um relatório publicado em 1946, que utilizaremos como base para o presente artigo, a CETex apresentou dados bastante interessantes sobre a situação da industrial têxtil brasileira no imediato pós-guerra. Ao todo, foram recenseadas 420 fábricas de fios, tecidos e artefatos de algodão, distribuídas em dezessete estados, mais o Distrito Federal (que, na época, era a atual cidade do Rio de Janeiro). As maiores concentrações estavam localizadas nos estados de São Paulo (com 223 fábricas), Minas Gerais (60), Rio de Janeiro (24), Pernambuco (17) e no Distrito Federal (15). Para além da evidente concentração industrial têxtil entre estados vizinhos na atual região Sudeste do país, convém ressaltar que também havia um número significativo de fábricas, relativamente próximas, entre Pernambuco, Alagoas (9) e Paraíba (5), algumas delas pertencentes à mesma companhia. Aliás, o mesmo também ocorria entre fábricas do Rio de Janeiro e Distrito Federal (CETEX, 1946, pp.103-104).

6 Vale ressaltar que, neste momento, a indústria têxtil de algodão era a que mais empregava operários no país e as maiores unidades fabris (em número de trabalhadores) estavam localizadas, respectivamente, nos estados da Paraíba (oito mil somente na fábrica Rio Tinto, da Companhia de Tecidos Paulista); Pernambuco (dez mil na fábrica Paulista, da mesma companhia, e cinco mil no Cotonifício Bezerra de Mello, em Recife); São Paulo (sete mil na Companhia Nacional de Estamparia e 5 mil na Indústrias Votorantim, ambas em Sorocaba); e o Distrito Federal (5 mil trabalhadores na Companhia América Fabril). Neste último caso, foi contabilizado o total de operários das quatro unidades da empresa localizadas na cidade do Rio de Janeiro: Cruzeiro, Bonfim, Mavilis e Carioca (CETEX, 1946, p.116 e 325).

7 Em relação ao estado do Rio de Janeiro, cuja capital era Niterói, esse relatório indicou, em página posterior, 25 fábricas de tecidos, ao invés das 24 , sob a ponderação de que foram realizados e utilizados mais de um "inquérito industrial", por isso as "divergências que se 
observam" (CETEX, 1946, p.354). De qualquer forma, foi verificado que as dez maiores fábricas têxteis fluminenses empregavam entre $1.001 \mathrm{e}$ duas mil pessoas, ou seja, $40 \%$ do total. Se considerarmos as unidades fabris com mais de quinhentos trabalhadores, esse percentual subiria para 56\%, totalizando catorze fábricas. (CETEX, 1946, p.117).

Dentre as 18.505 pessoas empregadas na indústria têxtil fluminense, distribuídas em treze municípios, cerca de quatro mil eram menores de idade (22\%). Do restante, homens e mulheres adultos correspondiam igualmente à faixa de sete mil trabalhadores ( $39 \%$ cada), inclusive destoando do panorama nacional, que apresentava um quadro de $44 \%$ de mulheres trabalhadoras têxteis, 36\% de homens e 20\% menores (CETEX, 1946, p.115).

Ao indicar dados específicos de cada uma das 25 fábricas têxteis de algodão no estado do Rio de Janeiro, o relatório permite vislumbrar as principais cidades polo do setor: Petrópolis (com seis unidades fabris), Magé (quatro), Valença (três), Niterói e Paracambi (duas cada), Nova Friburgo, Campos, Três Rios, Cordeiro, Vassouras, Miracema, Barra do Piraí e São João de Meriti (uma cada).

No entanto, é preciso ir além da quantidade de fábricas por município para dimensionar adequadamente esses polos. Considerando somente as unidades fabris de maior porte, entendidas no presente artigo como aquelas que mantinham mais de mil pessoas empregadas, o município de Magé tomaria a dianteira (com quatro fábricas), depois Petrópolis (com duas), seguida de Niterói, Paracambi, Nova Friburgo e Campos (uma cada), totalizando dez fábricas. Já em número de operários, os principais polos são os municípios de Magé (com 5.052 trabalhadores), Petrópolis (4.532), Niterói (2.594), Paracambi (1.550), Valença (1.414), Nova Friburgo (1.206) e Campos (1.086).

TABELA 01. Fábricas Têxteis de Algodão no Estado do Rio de Janeiro (1946)

\begin{tabular}{|c|c|c|c|c|}
\hline UNIDADES FABRIS & $\left|\begin{array}{c}\text { OPERARIOS } \\
\text { POR FABRICA }\end{array}\right|$ & MUNICIPIO & $\begin{array}{l}\text { SUBTOTAL } \\
\text { FABRICAS }\end{array}$ & $\begin{array}{l}\text { SUBTOTAL } \\
\text { OPERARIOS }\end{array}$ \\
\hline Petropolitana & 1.595 & \multirow{6}{*}{ Petrópolis } & \multirow{6}{*}{06} & \multirow{6}{*}{4.532} \\
\hline Cometa & 1.252 & & & \\
\hline Cometa $^{(1)}$ & $\ldots$ & & & \\
\hline Dona Isabel & 666 & & & \\
\hline São Pedro Alcâncara & 647 & & & \\
\hline Artur Bastos & 372 & & & \\
\hline Andorinhas & 1.586 & \multirow{4}{*}{ Magé } & \multirow{4}{*}{04} & \multirow{4}{*}{5.052} \\
\hline Santo Aleixo & 1.289 & & & \\
\hline Pau Grande & 1.109 & & & \\
\hline Mageense & 1.068 & & & \\
\hline Ferreira Guimarães & 589 & \multirow{3}{*}{ Valença } & \multirow{3}{*}{03} & \multirow{3}{*}{1.414} \\
\hline Progresso de Valença & 495 & & & \\
\hline Santa Rosa & 330 & & & \\
\hline $\begin{array}{l}\text { Manufatora Fluminense } \\
\text { |Marui }\end{array}$ & $\begin{array}{r}1.906 \\
688\end{array}$ & Niterói & 02 & 2.594 \\
\hline Brasil Industrial & 1.381 & \multirow{2}{*}{ Paracambi } & \multirow{2}{*}{02} & \multirow{2}{*}{1.550} \\
\hline Maria Cândida & 169 & & & \\
\hline Arp & 1.206 & Nova Friburgo & 01 & 1.206 \\
\hline Campista & 1.086 & Campos & 01 & 1.086 \\
\hline Industrial Fluminense & 324 & Três Rios & 01 & 324 \\
\hline Nossa Senhora da Piedade & 321 & Cordeiro & 01 & 321 \\
\hline São Luis & 210 & Vassouras & 01 & 210 \\
\hline São Martino & 155 & Miracema & 01 & 155 \\
\hline Amaniú & 61 & Barra do Piraí & 01 & 61 \\
\hline José Nora ${ }^{(2)}$ & $\ldots$ & São João de Meriti & 01 & - \\
\hline & & TOTAL & 25 & 18.505 \\
\hline
\end{tabular}

(1) A Cometa foi contabilizada com duas unidades fabris, porém centralizando o total de operários. Talvez este seja o motivo da divergência contida na publicação, entre 24 ou 25 fábricas.

(2) Não foi indicada a quantidade de operários da fábrica José Nora (CETEX, 1946, pp.322-323). 
11 Interessante observar que, nos anos de 1948 e 49, muitos desses polos têxteis protagonizaram um intenso ciclo de greves de trabalhadores, sobretudo nas fábricas dos municípios de Magé, Niterói, Nova Friburgo e Petrópolis. O movimento reivindicava o cumprimento imediato do reajuste salarial de $40 \%$, estabelecido pelo Tribunal Regional do Trabalho do Rio de Janeiro (TRT-RJ) em dissídio coletivo no ano anterior, e o fim da chamada Lei de Assiduidade Integral, que condicionava o aumento de salário do trabalhador à ausência de faltas e/ou atrasos do trabalhador. Ao todo, treze fábricas fluminenses foram mobilizadas e, como pano de fundo desses conflitos, estava justamente o processo de mobilização das indústrias têxteis a partir do contexto da Segunda Guerra Mundial (AMARAL, 2016, pp.162-163; e RIBEIRO, 2015, pp.128-129).

Portanto, visando compreender mais detidamente os (des)caminhos da indústria fluminense de tecidos de algodão no contexto pós-guerra, com ênfase nas relações capital-trabalho, propomos um estudo sobre as quatro fábricas têxteis do município de Magé, que estavam entre as dez maiores unidades fabris do setor no estado, todas com mais de mil trabalhadores. Nosso principal objetivo será analisar e distinguir as ações empresariais para além do espaço fabril, aspecto privilegiado sobre o setor têxtil nos estudos acadêmicos que foram desenvolvidos após a obra seminal de Stanley Stein, como veremos a seguir.

\section{0 pós-guerra e os estudos sobre têxteis no Brasil}

Enquanto alguns industriais investiram parte do capital financeiro adquirido durante a guerra na reforma de suas unidades fabris, na introdução de novos equipamentos, maquinário e processos industriais; outros buscaram somente aproveitar a efêmera proeminência do Brasil no mercado mundial de tecidos para auferir lucros com as exportações, descuidando do reaparelhamento de suas fábricas.

14 Ao fim da guerra, passado o período de "grande prosperidade", o quadro geral da indústria têxtil no Brasil já havia se alterado drasticamente, com os tradicionais fornecedores de tecidos se organizando para retomar seus mercados e os produtos brasileiros com dificuldades de enfrentar a concorrência desses países. Por outro lado, ao relegar o consumo interno em prol dos lucros no exterior, os industriais acabaram provocando a escassez e o encarecimento dos tecidos no mercado brasileiro, o que inclusive motivou o governo a suspender as exportações, a contragosto dos empresários têxteis.

Os representantes da indústria protestaram contra estas medidas, responsabilizando-as pela perda dos mercados externos. (...) Tanto falaram em "bancarrota", em "crise" e em "superprodução", caso o governo não liberasse e amparasse as exportações, que acabaram despertando verdadeiro clamor público. Elevou-se no pós-guerra um ressonante coro de críticas contra os empresários que insistiam em dizer que só as exportações, subvencionadas pelo governo, poderiam dar vazão aos excedentes de produção. (...) Dizia-se que não tinham razão nenhuma para reclamar, pois a íntima convivência indústria-governo só lhes trouxera vantagens, sob a forma de tarifas e subsídios (...). A opinião pública, indignada, exigia agora que a indústria têxtil cumprisse com os compromissos decorrentes de seus privilégios. Chegara, finalmente, a hora de acertar as contas. (...) A análise das origens e da natureza da insatisfação popular contra os empresários têxteis no pósguerra coloca em evidência algumas das deficiências da próspera e centenária indústria de tecidos do Brasil. (...) Durante a guerra, as fábricas de tecidos proporcionaram generosos dividendos aos seus diretores e acionistas. Aos 
consumidores, tocara a outra face desta prosperidade: a escassez e a carestia (STEIN, 1979, p.168 [1957]).

Por ironia, o mesmo discurso patriótico e nacionalista que impulsionou os trabalhadores ao "esforço de guerra" foi utilizado por eles para criticar os industriais têxteis, acusados de não se sujeitarem ao "sacrifício" e às "concessões", como seus empregados, estando mais preocupados em enriquecer exportando tecidos caros do que fabricar produtos populares para os brasileiros, seus compatriotas. "A guerra contribuíra, ainda que indiretamente, para que os trabalhadores brasileiros adquirissem nova consciência de sua importância na economia nacional" (STEIN, 1979, p.178 [1957]).

As décadas posteriores à guerra, portanto, foram marcadas por fortes tensões entre o empresariado têxtil e seus trabalhadores organizados, englobando debates sobre produção, faturamento, investimentos, desenvolvimento nacional, relações de trabalho, aplicação da legislação trabalhista e luta por "novos direitos". Sobre as relações capitaltrabalho, particularmente, os padrões tradicionais de administração de empresas utilizados com sucesso pela indústria têxtil de algodão desde o início do século XX- cuja tônica era o paternalismo - tornavam-se alvo de críticas no contexto pós Segunda Guerra Mundial (STEIN, 1979, p.187 [1957]).

Por sinal, os principais trabalhos sobre indústria têxtil no Brasil publicados desde o clássico de Stein buscaram refletir, em grande medida, sobre essas tensões. Destacamos aqui as obras do sociólogo Juarez Brandão Lopes, lançada em 1967, e do antropólogo José Sérgio Leite Lopes, em 1988, ambas como resultado de pesquisas de campo realizadas na década anterior às publicações.

Brandão Lopes produziu uma pesquisa pioneira sobre o operariado fabril, a partir de um estudo de caso sobre as relações industriais em duas comunidades da Zona da Mata Mineira que continham fábricas têxteis. Embora fuja aos interesses deste artigo uma abordagem mais detalhada deste importante trabalho, faz-se necessário observar que o autor tinha como importante referência as considerações do próprio Stein, que ao final do seu livro enfatizou a necessidade da "modernização dos métodos de administração", tida como "o maior desafio que se colocava para os empresários têxteis brasileiros" em meados do século XX (STEIN, 1979, p.184 [1957]). Ressaltamos que Brandão Lopes utilizou em seu estudo como referência a obra de Stein em inglês.

Dessa forma, o sociólogo buscava compreender o ajustamento do trabalhador a essa "nova" indústria, que seria marcada pela "quebra do padrão patrimonialista de relações de trabalho", revelando importantes processos de mudança, e por isso considerada como " $a$ trava mestra da ordem tradicional no Brasil" (LOPES, 1967, p.1).

Embora essa pesquisa tenha se tornado um clássico, fundamental para os estudos sobre trabalhadores no Brasil, seu legado acadêmico, vinculado a uma série de estudos sociológicos das décadas de 1950 e 60, acabou inculcando visões depreciativas em relação ao mundo rural, inspirados pela noção de modernização. Assim, consolidou-se no imaginário acadêmico uma divisão estrutural que caracterizou o rural como sinônimo de atraso e o urbano como progresso. A despeito de eventuais críticas, destacamos a relevante contribuição desse autor para a sociologia, sobretudo por seu pioneirismo ao investir em "estudos de caso", tendo esta noção modernizadora sido reforçada mais pelos estudos inspirados em Brandão Lopes do que propriamente nos trabalhos do autor (Lopes, 1987). 
21 Posteriormente, a antropologia social do trabalho passou a apresentar relevantes estudos sobre têxteis. A principal referência nessa área, sem dúvida, é a obra de José Sérgio Leite Lopes, autor de diversos trabalhos sobre o tema. Um deles, em especial, se tornou um clássico, no estudo sobre os operários da Companhia de Tecidos Paulista, localizada nos arredores de Recife. Realizando dezenas de entrevistas com trabalhadores têxteis, o antropólogo desenvolveu o conceito de uma forma de dominação fabril bastante peculiar, denominada como "padrão fábrica com vila operária" e definida enquanto resultado de uma configuração específica da relação entre a força de trabalho industrial e o patronato, que se constitui em "uma situação onde a própria fábrica é proprietária das casas em que moram seus operários e é promotora da vida social extra-fabril da localidade" (LOPES, 1988, p.17).

No entanto, embora a literatura frequentemente sugerisse que uma "fraca" militância política estaria associada ao controle patronal exercido sobre as formas de moradia dos trabalhadores, a pesquisa de Leite Lopes demonstrou como "as contradições e os conflitos são inseparáveis da própria apresentação analítica da dominação", onde a visão de grandeza da "cidade das chaminés" - representada pelo poder da fábrica de tecidos - dialogava com uma forte visão crítica sobre ela - representada pela "grandeza" do movimento operário local (LOPES, 1988, p.22 e 591). Mais recentemente, ao retomar contato com seus entrevistados da década de 1970, o autor participou da coprodução do documentário "Tecido Memória", ao lado de Rosilene Alvim e Celso Brandão. ${ }^{2}$

Em certa medida, podemos afirmar que o trabalho de Leite Lopes foi um dos pioneiros em analisar trabalhadores têxteis no Brasil como sujeitos e atores sociais conscientes, capazes de influir decisivamente no processo histórico. As análises de Stein e Brandão Lopes, este em menor grau, estiveram preocupadas principalmente com as questões dos industriais e de suas unidades fabris.

Portanto, é a partir do "padrão fábrica com vila operária", conceito construído por José Sérgio Leite Lopes, que o presente artigo pretende analisar as fábricas têxteis de Magé. Elas foram instaladas no município durante o século XIX, em grande medida por conta do considerável potencial hidráulico da região, cortada por diversos rios oriundos da Serra dos Órgãos. Ao todo, foram fundadas quatro unidades têxteis: Fábrica Nacional de Santo Aleixo (1848), Fábrica de Tecidos Pau Grande (1878), Companhia de Fiação e Tecidos Andorinhas (1890) e Companhia de Fiação e Tecidos Mageense (1891).

Os nomes destacados serão utilizados neste estudo para se referir às respectivas unidades fabris, pois eles acabaram se popularizando a despeito das alterações de propriedade e do nome oficial de cada uma dessas empresas ao longo do tempo. Nesse ínterim, cabem algumas observações sobre a fábrica Pau Grande: embora tenha sido construída em 1878, seu registro na Junta Comercial só ocorreu no ano seguinte, com a firma Santos, Peixoto \& Cia. Em 1885, é que ela passou a ser gerida pela sociedade anônima Companhia de Fiação e Tecidos Pau Grande. Posteriormente, com a aquisição da fábrica Cruzeiro, na cidade do Rio de Janeiro, essa sociedade foi transformada, no ano de 1892, em Companhia América Fabril. A empresa adquiriu maior projeção no país no cenário econômico pós Primeira Guerra Mundial (1914-1918) e se tornou, entre as décadas de 1920 e 30, a mais importante empresa brasileira do ramo têxtil (WEID, 1986, p.59 e 133). 


\section{Padrões e peculiaridades das fábricas com vila operária}

26 Em Magé, a Companhia América Fabril foi pioneira no projeto "fábrica com vila operária", posto em prática a partir da última década do século XIX, enquanto que os investimentos das fábricas Andorinhas e Santo Aleixo ainda eram escassos nesse sentido, só ocorrendo de forma mais efetiva após a década de $1930{ }^{3}$

Na realidade, as fábricas Pau Grande, Andorinhas e Santo Aleixo, em dado momento, construíram vilas para seus empregados. A exceção seria a fábrica Mageense, localizada no centro da cidade, que chegou construir casas para trabalhadores, porém sem as características de um bairro operário. Também cabe assinalar a existência das vilas das fábricas Estrela e Meio da Serra. Esta, também do ramo têxtil e batizada com o nome de Cometa, localizava-se bem na divisa com o município de Petrópolis, sendo inclusive motivo de disputas fiscais entre Magé e a cidade serrana; ao passo que aquela se dedica à produção de pólvora e estava situada na Raiz da Serra, em Magé, sendo administrada à época pelo Ministério da Guerra e atualmente pelo Exército Brasileiro (EB). Apesar dessas duas fábricas não configurarem como objeto de análise neste trabalho, julgamos interessante a citação, devido ao padrão semelhante às demais.

Essa combinação de fábrica com vila operária é bastante recorrente na bibliografia sobre industrialização e memória da classe trabalhadora, em diferentes campos de análise nas ciências sociais. Inclusive, diversos trabalhos citam as vilas operárias construídas pelas fábricas de tecidos em Magé.

Os estabelecimentos têxteis com moradias para trabalhadores foram uma característica do desenvolvimento industrial no interior do Estado do Rio de Janeiro. Exemplos são a 'Fábrica Esther' e a 'Fábrica Andorinhas', em Santo Aleixo, e o ‘Cotonifício Levy Gasparian', estabelecido em Três Rios. A ‘Fábrica de Tecidos e Fiação Pau Grande’, fundada em Magé em 1878, gerou um importante núcleo fabril - Pau Grande, que nos anos de 1950 e 1960 tornou-se famosa como o local onde Mané Garrincha nasceu e começou sua carreira. A 'Companhia América Fabril' foi proprietária de várias fábricas no Estado do Rio de Janeiro, todas fornecendo casas para seus operários. Além de Pau Grande, contava com outras fábricas com moradias (GUNN, 2005, p.29). ${ }^{4}$

Vale ressaltar que, desde a década de 1940, o próprio governo brasileiro começou a intensificar investimentos na construção de vilas operárias circunvizinhas às fábricas das empresas estatais. Há exemplos no próprio estado do Rio de Janeiro, como a construção da Fábrica Nacional de Motores (FNM), na localidade de Xerém, em Duque de Caxias, na Baixada Fluminense. Construída durante o Estado Novo e impulsionada pelo contexto da Segunda Guerra Mundial, a fábrica se notabilizou por sua localização isolada, pela construção de vilas operárias, bem como por seu investimento na autossuficiência de uma "Cidade dos Motores", que produziria seus próprios alimentos e teria seu comércio particular. Da mesma forma, esta indústria "de ponta" mantinha relações de trabalho bastante marcadas pelo exercício da subordinação com "características militares, paternalistas e de controle social", com enorme ingerência na vida do trabalhador fora da fábrica (RAMALHO, 1989, p.18).

Outro exemplo foi a construção da Usina Presidente Vargas, pela Companhia Siderúrgica Nacional (CSN), na localidade de Santo Antônio da Volta Redonda, no Vale do Paraíba, que logo tornou-se um ícone do desenvolvimento econômico brasileiro no pós-guerra. 
Afastada dos grandes centros urbanos, Volta Redonda foi emancipada do município de Barra Mansa e se transformou na cidade símbolo do trabalhismo, a "Cidade do Aço". Na realidade, o município resumia-se a própria fábrica. Seu complexo fabril foi considerado um modelo de cidade industrial para o país, habitada igualmente por "operários modelo", que formavam a "grande familia siderúrgica", na simbologia de um novo trabalhador para um novo país (SILVA, 2011, pp.90-91).

Pela mística e pelas condições que cercaram a constituição da CSN, a construção da usina e da cidade, pode-se dizer, sem temer cair em exagero, que Volta Redonda foi para os anos de 1940 o que a construção de Brasília representaria na segunda metade dos anos de 1950 (MOREL, 2001, p.51).

31 A principal referência em muitas dessas pesquisas, conforme já apontamos, é a obra de José Sérgio Leite Lopes. Entretanto, convém registrar que há debates conceituais que distinguem o "padrão fábrica com vila operária" de uma "company town" (Paz, 2011). A própria CSN, por exemplo, já foi analisada sob as duas perspectivas (Correia, 2001). Nesse sentido, reforçamos a necessidade de se aprofundar essas discussões, a fim de evitar inadequações no uso dos conceitos. Em relação ao "padrão fábrica com vila operária", especificamente, não podemos lançar mão desse conceito sem uma análise densa, verificando possíveis aproximações com o respectivo objeto de pesquisa, bem como sua viabilidade metodológica. No presente artigo, a proposta é analisar caso a caso as fábricas instaladas no município, buscando indicar - ainda que preliminarmente - similaridades e peculiaridades ao padrão estudado por Leite Lopes.

Nesse ínterim, compreendemos os bairros industriais de Magé como um "caso particular do possível, no universo do padrão fábrica com vila operária" (LOPES, 1988, p.20). Por isso, faz-se necessário mapear tanto suas particularidades em relação a outros municípios, quanto as distinções entre as diversas vilas operárias do município. Com base em diversas pesquisas publicadas sobre estes empreendimentos, buscaremos pontuar aspectos que julgamos esclarecedores às questões levantadas na pesquisa.

De fato, a vila operária em Pau Grande apresentava certas peculiaridades, principalmente pelo fato de ser um bairro mais afastado do restante do distrito onde estava localizada, existindo inclusive uma cerca ao redor do bairro e um pórtico com guardas da empresa em sua entrada. Nesse sentido, Pau Grande chegou a ser considerada uma "cidade quase que independente do municíío" (SANTOS, 1957, p.170). De fato, o bairro destoava do restante de Inhomirim ( $6^{\circ}$ distrito de Magé), que possuía extensas terras oriundas das antigas fazendas do período imperial, todas já decadentes. A malha ferroviária da Estrada de Ferro Leopoldina também cortava o distrito, o que contribuiu decisivamente para a ocupação dessa região durante a "febre de loteamentos", intensificada a partir da década de 1950. Atualmente, o bairro de Piabetá (localizado nas proximidades da antiga estação de trem "Entroncamento") é considerado o segundo maior núcleo urbano de Magé e o principal centro comercial no município.

34 Os militantes comunistas, por exemplo, comparavam o bairro operário aos espaços prisionais típicos de regimes autoritários. O vereador e dirigente sindical Astério dos Santos chegou a declarar, em outubro de 1959, durante o IV Congresso Fluminense de Municípios, que o bairro de Pau Grande seria um "Campo de Concentração" (CMM, livro de atas 21, fls.1v-2).

Anos antes, em 1953, o jornal Imprensa Popular identificava o bairro como um "feudo encravado na raiz da serra de Magé", explorando trabalhadores na fábrica e na lavoura (IMPRENSA POPULAR, 04/03/1953, p.6). Além disso, o mesmo periódico, ao fazer a 
cobertura de uma eleição no sindicato dos têxteis local, informava que os trabalhadores votariam separadamente, de acordo com as seções existentes na fábrica, entre elas a seção da "Lavoura" (IMPRENSA POPULAR, 21/07/1954, p.2). Em outro jornal, a "seção da Lavoura" foi chamada de "escritório da Lavoura" (O GLOBO, 13/01/1958, p.3).

Durante a década de 1960, a própria Companhia América Fabril, em anúncio publicado na imprensa carioca, valorizava a estrutura em torno de suas quatro fábricas de tecidos distribuídas nos estados do Rio de Janeiro e da Guanabara (à época Brasília já era Distrito Federal). Na peça publicitária, acompanhada por uma fotografia da vila operária em Pau Grande, a empresa enfatizava que, embora as fábricas formassem um "município", elas "não tinham prefeitura", numa clara referência a autossuficiência da empresa: "Somos uma cidade. Escola, igreja, ruas pavimentadas, casas, jardins, hospital, farmácia, dentista e campo de futebol. Até lavoura e pecuária" (O GLOBO. 06/11/1964. p.3).

De qualquer forma, reiteramos que convém certa precaução ao investir no termo "comunidade fechada", pois ele denota aspectos semelhantes à de uma "instituição total", o que não é o caso. Aliás, estudos específicos sobre esta mesma fábrica já apontaram que a vida social cotidiana desses trabalhadores têxteis revela diversas formas de resistência, inclusive no próprio espaço fabril.

Até mesmo dentro da fábrica, uma certa indisciplina e uma "cultura de oficina" podem desenvolver-se, parecendo quase indispensáveis para a boa gestão da produção. Além disso, graças à exploração autônoma de recursos oferecidos pela empresa - como a concessão de roçados operários ou de terrenos para cultivo, o uso das matas ao redor para fins materiais (lenha) ou para lazer (caça, especialmente de pássaros) -, esses operários, geralmente de origem camponesa, beneficiavam-se de condições de vida mais favoráveis do que poderíamos presumir, tendo em vista apenas os seus empregos industriais. Outras estruturas ainda estavam à sua disposição, como assistência médica, associações religiosas, grupos folclóricos, casa (...) e o clube de futebol (MARESCA, 1992, p.121).

No que se refere a essas estruturas à disposição dos operários de Magé, convém pontuar que a fábrica Pau Grande permaneceu, desde o século XIX até a década de 1970, administrada pela Companhia América Fabril, enquanto as demais fábricas de tecidos do município passaram por diversos proprietários, o que implicou em variadas formas de investimento dessas indústrias na vida social extrafabril.

A fábrica Mageense, que estava localizada na sede do município ( $1^{\circ}$ distrito), pertencia durante a guerra à Companhia Industrial Santo Amaro e estava inteiramente inserida ao centro urbano. Muito embora encontremos investimentos dessa empresa no ambiente extrafabril, sua atuação nos parece pouco significativa, sobre este aspecto, em comparação com as demais fábricas analisadas, principalmente após ter enfrentado uma grave crise, em 1952, quando encerrou suas atividades e provocou a venda da massa falida da companhia no ano de $1956 .{ }^{5}$

40 Ao reiniciar suas atividades, tendo como nova proprietária a Fábrica Itatiaia de Tecidos S/ A, a direção da fábrica buscou promover "imediata e completa recuperação das casas de moradia dos operários" e colaborar "materialmente na urbanização das terras onde se encontra localizada" (SANTOS, 1957, p.172).

41 Interessante observar que, durante aquela crise, outras fábricas têxteis do município conseguiram incorporar boa parte dos operários desempregados. "Certa ocasião, a Fábrica Itatiaia [Companhia Santo Amaro] parou de funcionar e as duas fábricas de Santo Aleixo mantiveram mais de 50\% dos funcionários daquela fábrica", recordou um antigo operário (Rocha, 1999). 
42 As fábricas localizadas em Santo Aleixo ( $2^{\circ}$ distrito) eram a Andorinhas, pertencente à empresa Fábricas Unidas de Tecidos, Rendas e Bordados S/A desde 1935; e a Santo Aleixo, incorporada à Companhia de Fiação e Tecelagem Bezerra de Mello em 1941. A partir dessas novas administrações, o pequeno distrito de Santo Aleixo foi submetido gradativamente a uma nova dinâmica social, que resultou na emergência de uma cultura fabril bastante específica, a partir da centralidade do trabalho industrial têxtil e dos seus reflexos para além dos muros da fábrica, abarcando as experiências cotidianas desses trabalhadores (MELLO, 2008, p.40).

43 Neste contexto, os nomes dos empresários que estavam à frente desses respectivos estabelecimentos industriais - Hermann Mattheis e Othon Lynch Bezerra de Mello marcaram profundamente a memória da localidade, sendo recorrentemente lembrados como benfeitores de "uma nova fábrica e também um novo Santo Aleixo" (SANTOS, 1957, p.162).

44 Cabe ressaltar que essas duas fábricas faziam parte de grandes e importantes conglomerados industriais no período pós Segunda Guerra. Além da Andorinhas, a empresa Fábricas Unidas de Tecidos, Rendas e Bordados S/A mantinha unidades fabris no Rio de Janeiro e na cidade fluminense de Valença. Já a Companhia de Fiação e Tecelagem Bezerra de Mello, além da Santo Aleixo, mantinha fábricas nos estados de Pernambuco, Alagoas e Minas Gerais, bem como chegou a adquirir, na década de 1950, a fábrica da Companhia Têxtil Brasil Industrial, na cidade fluminense de Paracambi (Keller, 1997).

Dotados de larga visão industrial, bastante inspirada nos modelos de cidades operárias americanas e europeias, os novos proprietários das fábricas no distrito de Santo Aleixo desenvolveram projetos voltados não apenas para suas empresas como também para a localidade circunvizinha: expandiram e aperfeiçoaram a geração hidroelétrica, para que assim atendessem com energia e água os habitantes, construíram vilas operárias para os trabalhadores, escolas, igrejas, ruas, praças, centros médicos, creches, cinemas, além de patrocinar grupos carnavalescos e clubes de futebol.

Estas transformações, indubitavelmente, impactaram a vida dos trabalhadores, sobretudo no que se refere a uma nova concepção de lar operário. A despeito das intenções patronais de "civilizar" e "modernizar" o cotidiano extrafabril dos trabalhadores, observamos que este conjunto de ações empreendidas pelas fábricas configurou como uma espécie de linha de colonização ou "frente avançada de povoamento" (OLIVEIRA, 1992, p.2), não apenas investindo na imobilização da força de trabalho, mas também como um símbolo dessas fábricas, servindo tanto como a materialização do seu discurso paternalista, quanto um dos principais elementos de sedução para recrutar novos trabalhadores (oferta de uma casa para morar). Grosso modo, buscava-se reforçar aspectos da "vida urbana" para as vilas operárias, como se as fábricas estivessem levando a "cidade" para o "interior". 6

(...) Em 1935, a fábrica [Andorinhas] possuía 70 casas para residências dos operários, sendo, na sua maioria, cobertas de zinco, não assoalhadas, sem instalações higiênicas e ainda, em grande parte, construídas de taboas e paus a pique. Essas casas, que não correspondiam às necessidades dos operários, foram demolidas e substituídas por moradias confortáveis, com todos os requisitos modernos, forradas, assoalhadas e com instalações de luz elétrica. Possui hoje a fábrica 200 casas, além das que se acham em construção e projeto. Graças ao desenvolvimento da empresa, como também da localidade em geral, a 'Andorinhas' possui os seguintes estabelecimentos, os quais não existiam em 1935: açougue, farmácia, alfaiataria, casas para hóspedes [pequeno hotel], restaurante, consultório médico, 
cinema, duas escolas, sendo uma mantida pela fábrica, estando já em projeto a construção de uma creche e um novo edifício para escola dotado de melhores acomodações com possibilidades para o ensino profissional, de acordo com a lei em vigor (O GLOBO, 09/09/1942, p.6). (1939-1945). Inevitavelmente, este contexto implicou de forma decisiva na (re)formação da classe trabalhadora local e na consolidação de uma cultura fabril. Durante a guerra, o distrito vivenciou inúmeras transformações, por meio de vínculos "densos" e de "longo alcance", mas que estavam diretamente ligadas às fábricas e seus trabalhadores, como a fundação do sindicato têxtil local, em 1941, de sua escola sindical dois anos depois, e a própria promulgação da Consolidação das Leis do Trabalho (CLT), em 1942; a difusão de uma forte política social por parte das fábricas (com a construção de vilas operárias, entre outras ações), além dos diversos incentivos fiscais obtidos por essas empresas no chamado "esforço de guerra", quando inclusive alguns direitos previstos na CLT chegaram a ser suspensos; além do fim do Estado Novo (1937-1945), seguido da forte atuação dos recémcriados partidos políticos, justamente no momento em que parte significativa dos trabalhadores brasileiros tornava-se eleitor.

50 Em meio a um forte discurso patriótico e nacionalista, típico deste período de conflito mundial, associado a um governo autoritário que apresentava uma legislação trabalhista como

"dádiva", mas que, logo em seguida, suprimiu parte dela em prol do esforço brasileiro para a guerra, os tecelões do distrito de Santo Aleixo passaram a ser tratados como verdadeiros "soldados da produção", sob o lema "trabalhar nas fábricas e lutar nas trincheiras" (O GLOBO, 09/09/1942, p.6).

(...) Santo Aleixo foi um dos distritos do Brasil que mais trabalharam pelo nosso esforço de guerra em prol da FEB. Os teares trepidavam dia e noite, o seu ruído varava as madrugadas. Nós nos matávamos nas horas extraordinárias para que os nossos pracinhas pudessem partir logo. Queríamos que eles fossem ajudar os nossos aliados no esmagamento, o mais rapidamente possível, da besta nazista (TRIBUNA POPULAR, 13/04/1946, p.8).

51

Inclusive, grande parte desse discurso mobilizador foi também reforçada pela militância do Partido Comunista do Brasil (PCB), que buscava atuar na associação que deu origem ao sindicato local, estrategicamente localizado na área fronteiriça entre as fábricas Andorinhas e Santo Aleixo, no bairro do Centro. Porém, inseridos em um contexto de forte enquadramento promovido pelo Estado Novo, a recém-criada entidade sindical têxtil, nas palavras do operário comunista José Rodrigues, teve que eleger como primeiro presidente "um homem de confiança da fábrica", tendo em vista que ele assumiria o cargo "num período de ditadura" (Rodrigues, 2006). 

trabalho, as políticas de gestão dessas indústrias têxteis em Santo Aleixo, buscaram corroborar os laços corporativos entre os trabalhadores, as empresas e, por extensão, o Estado, levando-se em conta a existência de um regime autoritário no país desde 1937, o Estado Novo. ${ }^{7}$

53

Por outro lado, muito embora a presença concreta dessas duas fábricas em diversos setores da vida do operariado, reforçada pela proximidade geográfica entre elas, poderia induzir uma análise dessas duas vilas operárias de forma contígua, faz-se necessário pontuar que existiam particularidades em cada complexo fabril.

No que tange às vilas operárias, por exemplo, ao passo que o grupo Bezerra de Mello investiu basicamente em "casas de família”, a Fábrica Andorinhas, dos Mattheis, chegou a construir moradias específicas para operários solteiros, que ficou conhecida popularmente como "quartinhos". Este aspecto implicava, obviamente, em estratégias específicas de contratação de mão de obra adotada por cada uma dessas empresas, sobretudo no período de maior oferta de empregos, no pós-guerra.

Além disso, podemos observar que as especificidades de cada complexo fabril refletiram decisivamente na construção de múltiplas identidades entre os trabalhadores do distrito. Para além de uma identidade social em comum, como se as duas comunidades fabris (trabalhadores e patrões) formassem uma "Grande Família", havia uma forte rivalidade entre os trabalhadores das duas fábricas, estendendo-se aos clubes de futebol e agremiações carnavalescas mantidas por elas. Eram os "de cima”, da fábrica Andorinhas, e os "de baixo", da fábrica Santo Aleixo. Ao mesmo tempo, observamos outro laço de identidade constituído na localidade, surgido a partir da demanda comum dos trabalhadores por direitos sociais e políticos diante das arbitrariedades das fábricas e, por consequência, do Estado, configurando uma rivalidade entre operários e patrões, por vezes simbolizada pelo sindicato, por algumas lideranças políticas ou por agremiações partidárias no pós-1945, o que lhe garantiu posteriormente o apelido de "Moscouzinho" (RIBEIRO, 2016, pp.157-159).

ale ainda ressaltar que as estratégias dos empresários têxteis, por diversas vezes, se associavam à política social da Igreja Católica, sobretudo por meio dos Círculos Operários, bem como se conjugavam com a atuação político partidária de lideranças do Partido Social Democrático (PSD). Tudo isso, sem dúvida, contribuiu para legitimar a visão do mito fundador de uma época áurea, que teria sido desencadeada a partir das administrações Mattheis e Bezerra de Mello, ao passo que também diferenciava bastante essas duas vilas operárias à que existia em Pau Grande, onde praticamente a fábrica exercia o "governo local de fato", semelhante ao caso de Paulista/PE (LOPES, 1988, p.192), muito embora em nenhum dos casos analisados em Magé verificou-se o cenário de isolamento, monopólio territorial e emancipação político-administrativa (com a criação de um novo município).

\section{Considerações finais}

57 Neste breve panorama, procuramos mapear algumas características da relação entre fábrica e operariado no município de Magé, bem como certas especificidades de cada complexo fabril. Tendo como enfoque o "padrão fábrica com vila operária", verificamos que essas empresas apresentavam diferentes modalidades de dominação social no 
município, contribuindo para reforçar diferenciações internas nesse grupo de trabalhadores. Por outro lado, embora as fábricas exercessem uma forte subordinação para além da esfera da produção, suas políticas sociais tornaram-se um símbolo de segurança, tranquilidade e aconchego no imaginário dos tecelões mageenses, até porque veio ao encontro a uma preocupação bastante cara à insegurança estrutural vivida pela classe trabalhadora, a moradia. Esse aspecto foi evidenciado tanto nas falas dos operários em diversos estudos sobre os têxteis no município, quanto em pesquisas que abordam outras regiões e categorias profissionais.

(...) A possibilidade de morar nas vilas aparece em boa parte dos depoimentos dos trabalhadores e funcionários como algo extremamente positivo, associado a outras 'vantagens' oferecidas pela fábrica para manter sob seu controle um grupo de trabalhadores essencial para seu funcionamento. A carência de tudo na vida dos trabalhadores, a necessidade do emprego, o bem-estar da família, pareciam argumentos mais fortes do que a evidente limitação imposta aos moradores das vilas (RAMALHO, 1989, pp.101-102).

58 O mais curioso é que, na historiografia sobre a indústria têxtil de algodão no Brasil, os termos "idade de ouro" normalmente são atribuídos ao contexto pós Primeira Guerra Mundial e à própria Segunda Guerra, o tal período de "grande prosperidade" apontado por Stein. Por vezes, a própria manutenção de ações paternalistas nessas fábricas a partir da década de 1950 são motivos de críticas ou indicações para um "fracasso" empresarial, do ponto vista do capital. Entretanto, nos estudos recentes dedicados aos trabalhadores têxteis, o termo "época de ouro" ou equivalente é constantemente atribuído ao contexto democrático de 1945 à 64, a partir de memórias operárias que conectam - de forma positiva - tanto os projetos paternalistas das fábricas, quanto a efervescência política sindical e partidária que reforçava a agência dos trabalhadores. Por sinal, é no período da ditadura militar que a indústria têxtil de algodão, tão importante nas principais greves das décadas de 1950 e 60, ingressa em um lamentável processo de desindustrialização, cujo debate não será possível aprofundar aqui.

59 A partir desses apontamentos iniciais, esperamos aprofundar o diálogo entre pesquisadora(e)s - dos diversos campos das Ciências Sociais - dedicados ao tema do trabalho têxtil no estado do Rio de Janeiro e também no país. Atualmente, desenvolvemos um projeto de pesquisa em estágio de pós-doutoramento na Universidade Federal Rural do Rio de Janeiro (UFRRJ), com financiamento da Fundação Carlos Chagas Filho de Amparo à Pesquisa do Estado do Rio de Janeiro (FAPERJ), que busca justamente mapear estudos sobre fábricas e trabalhadores têxteis no Brasil, visando traçar um panorama mais abrangente da produção historiográfica sobre esse ramo industrial, permitindo pensar a categoria mais a nível "nacional", a partir do fomento de canais de diálogo entre autora(e)s. ${ }^{8}$

60 Portanto, esta abordagem específica sobre as indústrias têxteis fluminenses se apresenta como um ponto de partida para futuras parcerias em pesquisa, eventos, publicações e projetos coletivos. 


\section{BIBLIOGRAFIA}

ALVIM, Rosilene. A sedução da cidade: os operários-camponeses e a Fábrica dos Lundgren. Rio de Janeiro: Graphia, 1997.

AMARAL, Luciana Pucu Wollmann do. Niterói Operário: trabalhadores, política e lutas sociais na antiga capital fluminense (1942-1964). Rio de Janeiro: tese de doutorado em História, Política e Bens Culturais, CPDOC/FGV, 2016.

BEAUCLAIR, Geraldo. Raízes da indústria no Brasil: a pré-indústria fluminense, 1808-1860. Rio de Janeiro: Studio F\&S Editora, 1992.

CORREIA, Telma de Barros. De vila operária a cidade-companhia: as aglomerações criadas por empresas no vocabulário especializado e vernacular. São Paulo: Revista Brasileira de Estudos Urbanos e Regionais, mai/2001. n.4. pp.83-98.

COSTA, Hélio da. Trabalhadores, sindicatos e suas lutas em São Paulo (1943-1953). In: FONTES, Paulo; FORTES, Alexandre; NEGRO, Antonio Luigi; SILVA, Fernando Teixeira da. Na luta por direitos: leituras recentes em História Social do Trabalho. São Paulo: Unicamp, 1999. pp.87-121.

GUNN, Philip; CORREIA, Telma de Barros. A industrialização brasileira e a dimensão geográfica dos estabelecimentos industriais. Revista Brasileira de Estudos Urbanos e Regionais. v.7. n.1. maio/2005.

KELLER, Paulo. Fábrica e Vila Operária: a vida cotidiana dos operários têxteis em Paracambi/RJ. Engenheiro Paulo de Frontin/RJ: Solon Ribeiro, 1997.

LOPES, Juarez Brandão. Crise do Brasil arcaico. São Paulo: Difel, 1967.

LOPES, José Sérgio Leite. Sobre os trabalhadores da grande indústria na pequena cidade: crítica e resgate da 'Crise do Brasil Arcaico'. In: [org.] Cultura \& identidade operária: aspectos da cultura da classe trabalhadora. Rio de Janeiro: Marco Zero; UFRJ, 1987. pp.147-170. A Tecelagem dos Conflitos de Classe na Cidade das Chaminés. Brasília:

Editora UNB; Marco Zero, 1988.

MARESCA, Sylvain; LOPES, José Sérgio Leite. A Morte da "Alegria do Povo". Rio de Janeiro: Revista Brasileira de Ciências Sociais, 1992. v. 20.

MELLO, Juçara da Silva Barbosa de. Fios da Rede: industrial e trabalhadores na criação e expansão de um grupo empresarial (1920-1949). Rio de Janeiro: tese de Doutorado em História, PUC-RIO, 2012.

Identidade, memória e história em Santo Aleixo: aspectos do cotidiano operário na construção de uma cultura fabril. São Gonçalo: dissertação de Mestrado em História Social, FFP/UERJ, 2008.

MOREL, Regina Lúcia M. A construção da "família siderúrgica": gestão paternalista e empresa estatal. In: RAMALHO, José Ricardo [org.]. Trabalho e tradição sindical no Rio de Janeiro: a trajetória dos metalúrgicos. Rio de Janeiro: DP\&A, 2001.

OLIVEIRA, Sônia Maria Gonzaga de. Montanhas de Pano: fábrica e vila operária em Santo Aleixo. Rio de Janeiro: dissertação de Mestrado em Antropologia Social, MN/UFRJ, 1992. 
PAZ, Adalberto Júnior Ferreira. Capital, trabalho e moradia em complexos habitacionais de empresa: Serra do Navio e o Amapá na década de 1950. In: AMARAL, Alexandre [et.al]. Do lado de cá, fragmentos de História do Amapá. Belém: Açaí, 2011. pp.461-468.

PESSANHA, Elina G. da Fonte; MOREL, Regina Lúcia de Moraes. Gerações operárias: rupturas e continuidades na experiência de metalúrgicos do Rio de Janeiro. Revista Brasileira de Ciências Sociais (RBCS). Rio de Janeiro: out/1991. a.6. n.17.

RAMALHO, José Ricardo. Estado Patrão e Luta Operária: o caso FNM. São Paulo: Paz e terra, 1989. RIBEIRO, Felipe. Memórias da Moscouzinho: os tecelões de Santo Aleixo e a liderança de Astério dos Santos. Jundiaí: Paco Editorial, 2016.

. A foice, o martelo e outras ferramentas de ação política: os trabalhadores rurais e têxteis de Magé/RJ (1956-1973). Rio de Janeiro: tese de doutorado em História, Política e Bens Culturais, CPDOC/FGV, 2015.

. Operários à tribuna: vereadores comunistas e trabalhadores têxteis de Magé (1951-1964). São Gonçalo: dissertação de mestrado em História Social, FFP/UERJ, 2009.

SANTOS, Renato Peixoto dos. Magé: Terra do Dedo de Deus. Rio de Janeiro: IBGE, 1957.

SILVA, Eduardo Ângelo da; SILVA, Leonardo Ângelo da. Industrialização, urbanização e formação de classe em Volta Redonda (1945-1979): do fim do Estado Novo aos tempos da ditadura. Revista Mundos do Trabalho, vol. 3, n. 5, janeiro-junho de 2011. pp.86-113.

STEIN, Stanley J. Origens e evolução da indústria têxtil no Brasil, 1850-1950. Rio de Janeiro: Campus, 1979.

WEID, Elisabeth von der; BASTOS, Ana Marta Rodrigues. O Fio da Meada: Estratégia e Expansão de uma indústria têxtil: Companhia América Fabril 1878/1930. Rio de Janeiro: Fundação Casa de Rui Barbosa, 1986.

\section{Entrevistas}

ROCHA, Casimiro Virgínio da. Entrevista concedida a Felipe Ribeiro. 1999.

RODRIGUES, José. Entrevista concedida a Felipe Ribeiro. 04/08/2006.

\section{Periódicos}

Imprensa Popular, O Globo e Tribuna Popular.

Atas Legislativas

CMM [Câmara Municipal de Magé]. Livro de Atas n.21 (10/11/1959 a 29/11/1960).

\section{Relatórios Ministeriais}

CETex [Comissão Executiva Têxtil]. Indústria Têxtil Algodoeira. Rio de Janeiro: Ministério do Trabalho, Indústria e Comércio, 1946.

\section{NOTAS}

1. Publicação original: STEIN, Stanley. The Brazilian Cotton Manufacture: Textile Enterprise in an Underdeveloped Area, 1850-1950. Cambridge: Harvard University Press, 1957.

2. Tecido Memória (2008). Disponível em <https://www.youtube.com/watch?v=MRsQU4Pt-QI>.

3. Há referências de que a fábrica Santo Aleixo, já em meados do século XIX, provia alojamentos para os seus empregados, tendo as mulheres um compartimento em separado. Esta iniciativa se 
justificava devido à distância que "naturalmente forçava a moradia no próprio local da produção", pois mais da metade dos trabalhadores da fábrica era composta por colonos alemães oriundos de Petrópolis (BEAUCLAIR, 1992. pp.146-147). No entanto, não consideramos este tipo de alojamento como inserido no padrão fábrica com vila operária, apontado por José Sérgio Leite Lopes.

4. A fábrica Esther, da citação, é a fábrica Santo Aleixo, que foi rebatizada pela Companhia Bezerra de Mello ao adquirir o estabelecimento, em 1941.

5. A crise desta fábrica foi abordada em minha dissertação de mestrado (Ribeiro, 2009, pp.178-181).

6. $O$ interior é aqui entendido como "categoria genérica que se refere aos mais diversos lugares de origem" e que "além da conotação de área distante, é também um local onde as pessoas são pobres e vivem ameaçadas em suas condições de sobrevivência” (Alvim, 1997, p.21).

7. Esses laços corporativos entre trabalhadores, empresa e Estado foram abordados por Elina Pessanha e Regina Morel ao analisarem o caso da CSN (Pessanha, 1991, p.74).

8. Projeto de Pós-Doutorado "Deu pano pra manga": Experiências de trabalhadores em fábricas de tecidos, da Segunda Guerra Mundial ao processo de desindustrialização, coordenado por Felipe Ribeiro (UFRRJ/FAPERJ).

\section{RESUMOS}

A indústria têxtil de algodão no Brasil foi bastante beneficiada durante a Segunda Guerra Mundial, sobretudo pela mobilização do chamado "esforço de guerra", ocasião em que direitos trabalhistas eram temporariamente suprimidos, bem como pelas oportunidades de inserção no mercado externo, inclusive com cotas estabelecidas por organismos internacionais. Visando compreender mais detidamente os (des)caminhos desse ramo industrial no estado do Rio de Janeiro, a partir do contexto pós-guerra, com ênfase nas relações capital-trabalho, propomos um estudo de caso sobre quatro fábricas têxteis que estavam entre as maiores unidades fabris fluminenses. Desse modo, principal objetivo deste artigo será analisar e distinguir as ações empresariais para além do espaço fabril, aspecto privilegiado sobre o setor têxtil brasileiro nos estudos acadêmicos.

The cotton textile industry in Brazil benefited greatly during World War II, above all by the mobilization of the so-called "war effort", at which time labor rights were temporarily suppressed, as well by as opportunities for insertion into the external market, including established of quotas by international bodies. Aiming to understand more thoroughly the ways of this industrial branch in the state of Rio de Janeiro, from the post-war context, with emphasis on relations capital-job, we propose a case study on four textile factories that were among the largest of state of Rio de Janeiro. Thus, the main objective of this article will be to analyze and distinguish the entrepreneurs actions for beyond the work space, a privileged aspect of the Brazilian textile sector in academic studies.

La industria textil de algodón en Brasil fue bastante beneficiada durante la Segunda Guerra Mundial, sobre todo por la movilización del llamado "esfuerzo de guerra", ocasión en que los derechos laborales eran temporalmente suprimidos, así como por las oportunidades de inserción en el mercado externo, incluso con cuotas establecidas por organismos internacionales. Con el fin 
de comprender más detenidamente los caminos de esta rama industrial en el estado de Río de Janeiro, a partir del contexto posguerra, con énfasis en las relaciones capital-trabajo, proponemos un estudio de caso sobre cuatro fábricas textiles que se encontraban entre las mayores unidades fabriles del estado de Rio de Janeiro. De este modo, el principal objetivo de este artículo será analizar y distinguir las acciones empresariales más allá del espacio fabril, aspecto privilegiado sobre el sector textil brasileño en los estudios académicos.

L'industrie textile de coton au Brésil a été largement bénéficiée pendant la Seconde Guerre mondiale, surtout par la mobilisation de l' 'effort de guerre», moment où les droits du travail ont été temporairement supprimés, ainsi que des opportunités d'insertion dans le marché extérieur, $\mathrm{y}$ compris par des quotas établis. par des organismes internationaux. Visant à mieux comprendre les (de)voies de cette branche industrielle dans l'état de Rio de Janeiro, á partir du contexte d'après-guerre, en mettant l'accent sur les relations capital-travail, nous proposons une étude de cas sur quatre usines textiles parmi les plus grandes industries fluminenses. Ainsi, l'objectif principal de cet article sera d'analyser et de distinguer les actions entrepreneuriales au-delà de l'espace de fabrication, aspect privilégié du secteur textile brésilien dans les études académiques.

\section{ÍNDICE}

Mots-clés: Industrie textile; Seconde Guerre mondiale; Vilage d'ouvriers; État de Rio de Janeiro.

Keywords: Textile industry; Second World War; Workers Village; Rio de Janeiro state.

Palabras claves: Industria textil; Segunda Guerra Mundial; Villa Obrera; estado de Río de Janeiro.

Palavras-chave: Indústria Têxtil; Segunda Guerra Mundial; Vila Operária; estado do Rio de Janeiro.

\section{AUTOR}

\section{FELIPE RIBEIRO}

Universidade Federal Rural do Rio de Janeiro (UFRRJ). Instituto Multidisciplinar. Professor em Estágio de Pós-Doutorado - FAPERJ. E-mail: felipe_ffp@yahoo.com.br 